University of Nebraska - Lincoln

DigitalCommons@University of Nebraska - Lincoln

March 1978

\title{
Magnetic ordering and local random anisotropy in dilute magnetic glasses
}

G.R. Gruzalski

University of Nebraska - Lincoln

J.D. Patterson

University of Nebraska - Lincoln

David J. Sellmyer

University of Nebraska-Lincoln, dsellmyer@unl.edu

Follow this and additional works at: https://digitalcommons.unl.edu/physicssellmyer

Part of the Physics Commons

Gruzalski, G.R.; Patterson, J.D.; and Sellmyer, David J., "Magnetic ordering and local random anisotropy in dilute magnetic glasses" (1978). David Sellmyer Publications. 175.

https://digitalcommons.unl.edu/physicssellmyer/175

This Article is brought to you for free and open access by the Research Papers in Physics and Astronomy at DigitalCommons@University of Nebraska - Lincoln. It has been accepted for inclusion in David Sellmyer Publications by an authorized administrator of DigitalCommons@University of Nebraska - Lincoln. 


\section{MAGNETIC ORDERING AND LOCAL RANDOM ANISOTROPY IN DILUTE MAGNETIC GLASSES}

R. R. Fruzaiski, J. D. Patterson, and D. J. Sellmyer

Behlen Laboratory of Physics, University of Nebraska, Lincoln, Nebraska 68588

\section{ABSTRACT}

Magnetic susceptibility and high-field magnetization measurements are presented for amorphous $\mathrm{Zr}_{40} \mathrm{Cu}_{60-x} \mathrm{M}_{x}$ (M denoting $\mathrm{Fe}, \mathrm{Mn}$, Gd, and $\mathrm{Tb}$ ) and $\mathrm{Nb}_{50} \mathrm{Ni}_{50-x} \mathrm{Fe}_{x}$, with $x$ ranging from zero to about ten. The alloys for $M=G d$, Tb, and Fe develop low-temperature ordered states that are characterized as spin glass like, whereas the Mn alloy exhibits no evidence of order down to $1.3 \mathrm{~K}$. The magnetic properties of these alloys are discussed in terms of local random anisotropy, fluctuations in the interimpurity exchange interactions, extremely short electron-mean-free paths, antiferromagnetic interactions between the localized moments and the conduction electrons, and moment instabilities.

\section{INTRODUCTION}

There is by now a considerable body of theoretical and experimental 1 iterature on the behavior of amorphous transition-metal alloys containing magnetic ions. Many of these alloys exhibit magnetic properties which are quite different from those of crystalline alloys of the same composition. Interpreting magnetic properties of these alloys is complicated because it is difficult to separate effects of chemical disorder (which refers to the number, species, and positions of an atom's near neighbors) from those of structural disorder (which denotes a lack of crystallinity). If unique calculations are to be made, the disorder must be sufficiently characterized; yet, one is usually content with understanding the behavior of an amorphous system vis-a-vis a crystalline system by categorizing the former as disordered in some general phenomenological sense. For example, one approach used to describe magnetism in amorphous metals is based on Gubanov's ideas [1] and uses phenomenological fluctuations in the interimpurity exchange interaction J. This approach can explain, for example, the observation that the ordering temperature and spontaneous magnetization of an amorphous alloy are often much lower than those of the corresponding crystalline alloy. An objection to this approach, however, is that it often requires fluctuations in $J$ of order $J$, which, at times, may be unlikely. A second approach is to ignore the fluctuations in the exchange and to subject each spin to a local uniaxial anisotropy field with random orientation. This second approach is the random anisotropy model of amorphous magnetism $[2,3]$.

of course, the problem of describing an amorphous magnetic material is far more complicated than choosing one of these two descriptions or some combination of them As already mentioned, one may wish to distinguish between the effects of chemical and structural disorder. One may also want to investigate the nature of the interaction, the effect of disorder on the local moment stability, the role of Kondoism, the effect of extremely short electron-mean-free paths, the effect of magnetic clustering, and so on.

Some of the above-mentioned effects have been studied by systematically investigating the magnetic properties of splat-cooled $\mathrm{Zr}_{40} \mathrm{Cu}_{60-x} \mathrm{M}_{x}$ (M denoting $\mathrm{Fe}, \mathrm{Mn}, \mathrm{Gd}$, and $\mathrm{Tb})$ and $\mathrm{Nb}_{50} \mathrm{Ni}_{50-x} \mathrm{Fe}_{x}$, with $x$ ranging from zero to about ten. These amorphous alloys were chosen for several reasons. Firstly, the magnetism in these alloys is expected to be due to localized moments. Secondly, in each of these alloys there exists only one type of "magnetic" atom; hence, interpreting the behavior of such alloys should be less difficult than for alloys containing two or more types of mag- netic atoms. Thirdly, these alloys are possible candidates for studying the effect of moment instabilities in that the $4 \mathrm{f}$ moments are expected to be stable whereas the $3 \mathrm{~d}$ moments may be unstable depending on their environment. The primary motivation for studying the rare-earth alloys was to investigate the effect of local random anisotropy. Because Gd is an S-state ion and $T b$ an $\mathrm{F}$-state ion, one would expect anisotropy effects to be considerably more pronounced in the Tb al loys than in the Gd alloys. Since these alloys have the same host, one would expect only small differences in the fluctuations in $J$ for alloys of equal concentration. Therefore, any differences in the magnetic behavior of these two systems, that could not be accounted for by a different de Gennes factor and/or different interaction between the conduction electrons and Tocalized moments, may be due to differences in the strength of the local random anisotropy. Furthermore, in magnetically dilute alloys of this type, it is possible to decrease the concentration to arbitrarily small values so that, in alloys for which random anisotropy is present, the effect of random anisotropy can be made to dominate that of interimpurity exchange.

In this article, some of the results of this investigation are reported and the behavior of these alloys is discussed in terms of many of the ideas mentioned above.

\section{EXPERIMENTAL}

The amorphous samples were produced by melting about $0.1 \mathrm{~g}$ of al7oy (prepared by arc melting) in a modified arc-melting furnace equipped with a copper plunger [4]. The alloys were quenched into foils about $60 \mu \mathrm{m}$ thick by rapidly propelling the plunger onto the melted alloy. From the velocity of the plunger (almost $10 \mathrm{~m} / \mathrm{sec}$ ), a cooling rate of $10^{6}-10^{7} \mathrm{~K} / \mathrm{sec}$ was estimated. The amorphous nature of all the alloys was confirmed by $x$-ray diffraction measurements.

High-field measurements of the magnetization M were made on a17 samples to $80 \mathrm{kOe}$ in a superconducting solenoid. These measurements were made with a vibrating-sample magnetometer (VSM) from 1.3 to about $80 \mathrm{~K}$.

Two techniques were used to measure the magnetic susceptibility $x$. The "zero-field" susceptibilities were determined from the VSM data at $\mathrm{H}=0$; only virgin-curve data were used for this purpose. The "low-field" susceptibility $x$ was measured with a standard Faraday technique between 1.5 and $300 \mathrm{~K}$. These measurements were made using various fields between 0.23 and $10.4 \mathrm{k} 0 \mathrm{e}$. Whenever possible, the data were taken at fields in the region where $M$ is linear in the applied field $H$. When this was not possible, the data were taken at fields as small as possible, yet still large enough to give reasonable signal to noise ratios. For example, the low-field $\mathrm{M}(\mathrm{H})$ data for $\mathrm{Zr}_{40} \mathrm{Cu}_{50} \mathrm{Fe}_{10}$ showed considerabie curvature over the entire temperature range and the $x$ data were taken at about $0.7 \mathrm{kOe}$.

\section{LOW-FIELD RESULTS AND DISCUSSION}

As an initial attempt to understand the behavior of these systems, the low-field susceptibility data were fitted to the Curie-Weiss expression $x-x_{0} \equiv \Delta x=c(T-\theta)^{-1}$. Values for $p_{\text {eff }}$ were obtained from $C$ in the usual way and values of the angular momentum $J$ were obtained using $p_{\text {eff }}=g[J(J+1)]$. 
Here $g$, the Landé g-factor, was assumed to be 2 for the samples containing $\mathrm{Mn}$ and $\mathrm{Fe}$ and, for the samples containing Gd and $\mathrm{Tb}, \mathrm{g}$ was calculated assuming trivalent ions. The results of the best fits obtained are shown in Table I. Except for a small upturn below about $50 \mathrm{~K}$ (presumably due to unwanted impurities), $x(T)$ for $\mathrm{Zr}_{40} \mathrm{Cu}_{60}$ is indicative of temperatureindependent Pauli paramagnetism and has a value of about $0.89 \mu$ emu/g. $X(T)$ for $\mathrm{Nb}_{50} \mathrm{Ni}_{50}$ shows essentially no temperature dependence and has a value of about $2.1 \mu \mathrm{emu} / \mathrm{g}$.

The samples containing $G d$ and Tb exhibit $p_{\text {eff }}$ values very close to those expected for trivalent ions subject to Hund's rules $\left(7.94\right.$ for $\mathrm{Gd}^{3+}$ and 9.72 for $\left(\mathrm{Tb}^{3+}\right)$. The positive values of $\theta$ for these samples indicate predominantly ferromagnetic interimpurity coupling. The rather small values of $p_{\text {eff }}$ for both the $\mathrm{Fe}$ and Mn alloys are suggestive of moment instabilities on at least some of the magnetic atoms and/or some antiferromagnetic clustering that subsists even at high temperatures. However, because the values of $p_{\text {eff }}$ are roughly independent of concentration for the $\mathrm{Nb}-\mathrm{Ni}(\mathrm{Fe})$ a) loys and $\mathrm{Zr}-\mathrm{Cu}(\mathrm{Mn})$ alloys (Mizoguchi [5] obtains $p_{\text {eff }}=1.6$ for a $6 \% \mathrm{Zr}-\mathrm{Cu}(\mathrm{Mn})$ alloy), it appears that the more important effect is that of moment instabilities. Furthermore, one expects that these ions will tend to lose their moments as their local environment goes from nearly al1 $\mathrm{Cu}$ (or $\mathrm{Ni}$ ) to nearly all $\mathrm{Zr}$ (or $\mathrm{Nb})[6]$. The negative $\theta$ values for these samples are suggestive of predominantly antiferromagnetic coupling, most probably between an impurity and the conduction electrons.

Figure 1 shows the low-field susceptibility data for $\mathrm{Zr}_{40} \mathrm{Cu}_{50} \mathrm{Mn} 10^{\circ}$. Note that there is no maximum in $x(T)$ down to $1.5 \mathrm{~K}$. Similarly, the low-field $x(T)$ for al1 the samples exhibits no evidence of a spin-nlasslike transition. However, zero-field susceptibility measurements did exhibit peaks in all the alloys except for the Mn alloy (and the $\mathrm{Nb}-\mathrm{Ni}(\mathrm{Fe})$ alloys, for which zero-field susceptibility was not determined). of course, it is possible that the strength of such interactions in, say $\mathrm{Zr}_{40} \mathrm{Cu}_{50} \mathrm{Mn}_{10}$, is so weak that spin-glass-like order would develop only at very low temperatures.

The low-field magnetization $M(H)$ measurements for the samples containing $\mathrm{Fe}$ show considerable curvature over the entire temperature range. For $\mathrm{Zr}_{40} \mathrm{Cu}_{50} \mathrm{Mn} 10^{\text {, }}$ low-field $M(H)$ data exhibit more curvature at room temperature than at lower temperatures. These data suggest the presence of magnetic clusters due to predominantly ferromagnetic near-neighbor interimpurity interactions. (Because these intracluster interactions apparently are larger than thermal energies even at room temperature, they do not affect the value of $\theta$.) In the case of the $\mathrm{Nb}-\mathrm{Ni}(\mathrm{Fe})$ alloys, the effect of these clusters was approximately taken into account [7] and values of $p_{e f f}$ of about 0.7 of those in Table I were obtained. A small amount of clustering was also in evidence in $\mathrm{Zr}_{40} \mathrm{Cu}_{57} \mathrm{Gd}_{3}$ at room temperature. With the possible exception of $\mathrm{Zr}_{40} \mathrm{Cu}_{50} \mathrm{Fe}_{10}$, it was concluded that the presence of clusters had little effect on the Curie-Weiss parameters.

\section{HIGH-FIELD RESULTS AND DISCUSSION}

Saturation did not occur in any of the samples, even at $80 \mathrm{kOe}$ and $1.3 \mathrm{~K}$; however, the alloys containing Gd approached normalized magnetization values (m) of unity. (Here $m=M / 7_{\mu_{B}}$ for the Gd alloys and $m=M / 9_{\mu_{B}}$ for the Tb alloys, where $M$ is the magnetization per impurity atom.) Note that for the Gd alloys,

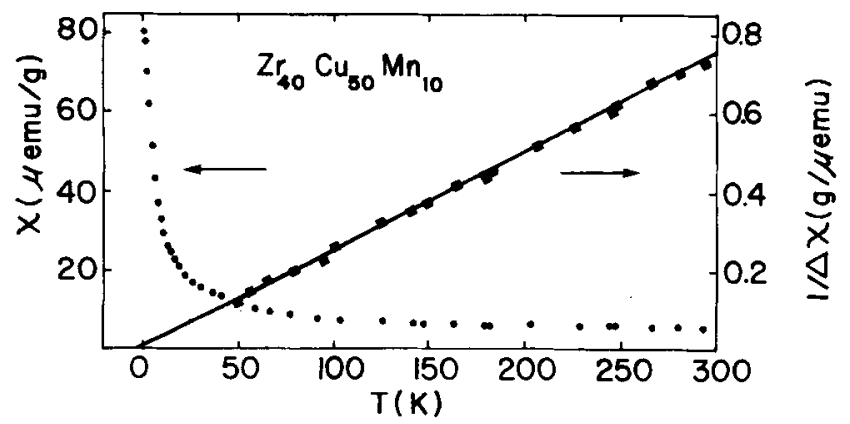

Fig. 1. $\dot{x}(T)$ and $1 / \Delta x(T)$ for amorphous $\mathrm{Zr}_{40} \mathrm{Cu}_{50} \mathrm{Mn}_{10}$.

TABLE I

Curie-Weiss parameters and $T_{C}$ (see text). ND denotes that $T_{C}$ has not been determined.

\begin{tabular}{|c|c|c|c|c|c|}
\hline Sample & $x_{0}(\mu e m u / g)$ & $\theta(K)$ & $p_{\text {eff }}$ & $\mathrm{J}$ & $T_{C}(K)$ \\
\hline $\mathrm{Nb}_{50} \mathrm{Ni}_{45} \mathrm{Fe}_{5}$ & 3.2 & -134 & 1.7 & 0.49 & ND \\
\hline $\mathrm{Nb}_{50} \mathrm{Ni}_{40} \mathrm{Fe}{ }_{10}$ & 5.7 & -79 & 1.7 & 0.49 & ND \\
\hline $\mathrm{Zr}_{40} \mathrm{Cu}_{50} \mathrm{Fe}_{10}$ & 9.7 & -33 & 2.8 & 0.99 & $\sim 4.3$ \\
\hline $\mathrm{Zr}_{40} \mathrm{Cu}_{50}{ }^{\mathrm{Mn}}{ }_{10}$ & 3.7 & -1.7 & 1.5 & 0.40 & $<1.3$ \\
\hline $\mathrm{Zr}_{40} \mathrm{Cu}_{57} \mathrm{Gd}_{3}$ & 6.9 & 13 & 8.0 & 3.5 & $<5$ \\
\hline $\mathrm{Zr}_{40} \mathrm{Cu}_{54} \mathrm{Gd}_{6}$ & 3.3 & 30 & 8.0 & 3.5 & -15 \\
\hline $\mathrm{Zr}_{40} \mathrm{Cu}_{57}^{\mathrm{Tb}} \mathrm{b}_{3}$ & 3.6 & 8 & 8.9 & 5.5 & -4.8 \\
\hline $\mathrm{Zr}_{40} \mathrm{Cu}_{54} \mathrm{~Tb}_{6}$ & 1.6 & 6 & 8.2 & 5.0 & $\sim 6.8$ \\
\hline
\end{tabular}

$m(H)$ lies above a simple Brillouin function at high temperatures, which also indicates that there exists a predominance of ferromagnetic interimpurity coupling in this alloy. Yet, at low temperatures, $m(H)$ approaches saturation more slowly than does a simple Brillouin function. This suggests the presence of some random antiferromagnetic interactions along with the ferromagnetic interactions. For the Tb alloys, $\mathrm{m}(\mathrm{H})$ approaches saturation much more slowly than does a simple Brillouin function over the entire temperature range $(m \simeq 0.5$ at $80 \mathrm{kOe}$ and low temperatures).

For the samples containing $\mathrm{Fe}$ and $\mathrm{Mn}, \mathrm{M}(\mathrm{H})$ is far from saturated at $80 \mathrm{kOe}$. For example, at $80 \mathrm{kOe}$ and $1.3 \mathrm{~K}, \mathrm{M}$ for $\mathrm{Nb}_{50} \mathrm{Ni}_{40} \mathrm{Fe}_{10}, \mathrm{Zr}_{40} \mathrm{Cu}_{50} \mathrm{Fe}_{10}$, and

$\mathrm{Zr}_{40} \mathrm{Cu}_{50} \mathrm{Mn}_{10}$ is $0.037_{\mu_{B}} / \mathrm{Fe}, 0.037_{\mu_{B}} / \mathrm{Fe}$, and $0.23_{\mu_{B}} / \mathrm{Mn}$,

respectively. Fluctuations in the exchange couplings $J$ are more than likely an important factor contributing to the small values of $M(H)$ as well as the slow approach to saturation. This behavior also is supportive of the ideas mentioned above regarding moment instabilities, antiferromagnetic interimpurity interactions, and antiferromagnetic coupling between the localized moments and the conduction electrons. Perhaps, too, some form of anisotropy is an important factor.

High-field hysteresis loops as in Fig. 2 were taken on some of the samples. In all cases, the field was taken to $80 \mathrm{kOe}$ in both directions. Also, in all cases, no "squaring off" of the hysteresis loop was observed.

The temperature dependence of the coercive or spin-reversal fields, $H_{C}$, was determined from the high- 


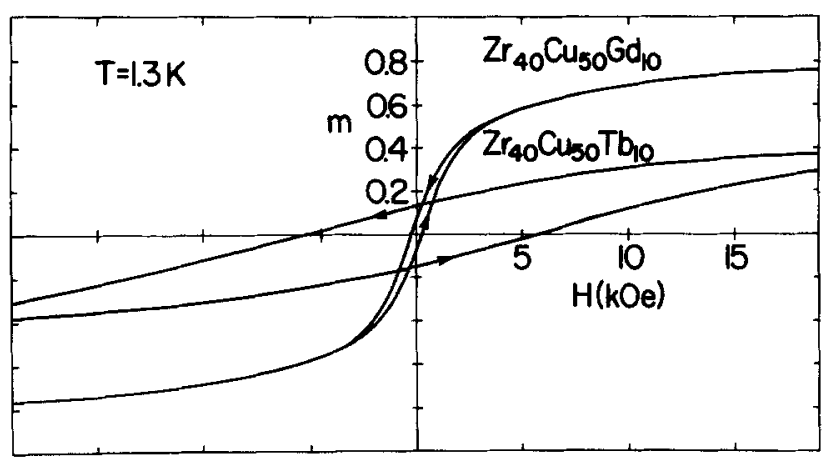

Fig. 2. $M(H)$ for $\mathrm{Zr}_{40} \mathrm{Cu}_{50^{G d}}{ }_{10}$ and $\mathrm{Zr}_{40} \mathrm{Cu}_{50} \mathrm{~Tb}_{10^{\circ}}$. Note that $H_{C}$ is much larger for the Tb alloy.

field hysteresis data. $H_{C}(T)$ for the $10 \% \mathrm{Gd}$ and $\mathrm{Tb}$ alloys is shown in Fig. 3. Note that the values of $\mathrm{H}_{\mathrm{C}}$ for the $\mathrm{Tb}$ alloy are an order of magnitude larger than for the Gd alloy. The hysteresis data were also used to determine "ordering temperatures" $T_{C}$, defined as that temperature for which $\mathrm{H}_{C}$ vanishes. Values of $T_{C}$ for most of the samples are given in Table $I$. At low temperatures, hysteresis did develop in ${ }^{\mathrm{Nb}}{ }_{50} \mathrm{Ni}_{40} \mathrm{Fe}_{70}$, suggestive of random ferromagnetic order, but not enough data was obtained to determine values of $\mathrm{T}_{\mathrm{C}}$ for the $\mathrm{Nb}-\mathrm{Ni}(\mathrm{Fe})$ alloys.

The temperature dependence and magnitude of $\mathrm{H}_{\mathrm{C}}$ and the behavior of $m(H)$ in the Gd and Tb alloys can be understood by assuming that a) the magnetic behavior of the fid alloys is affected primarily by fluctuations in $J$, and b) that of the Tb alloys is due primarily to the existence of local anisotropy fields of random orientation. This follows for several reasons. First of a11, the rapid increase in $\mathrm{H}_{\mathrm{C}}$ with decreasing temperature for $\mathrm{Zr}_{40} \mathrm{Cu}_{50} \mathrm{~Tb}{ }_{10}$ (Fig. 3) is reminiscent of what we [3] have obtained in a calculation using the random anisotropy model. Secondly, the large values of $H_{C}$ for the Tb alloys as compared to those for the Gd alloys can be understood in terms of spins getting "blocked" in the Th alloys by the energy barrier produced by crystal field anisotropy. Furthermore, preliminary fits [8] of our $m(H)$ data indicate that the behavior of the Gd alloys is explicable in terms of a Heisenberg model with fluctuating 3 , whereas the data for the Tb alloys can be well fitted by the random anisotropy model.

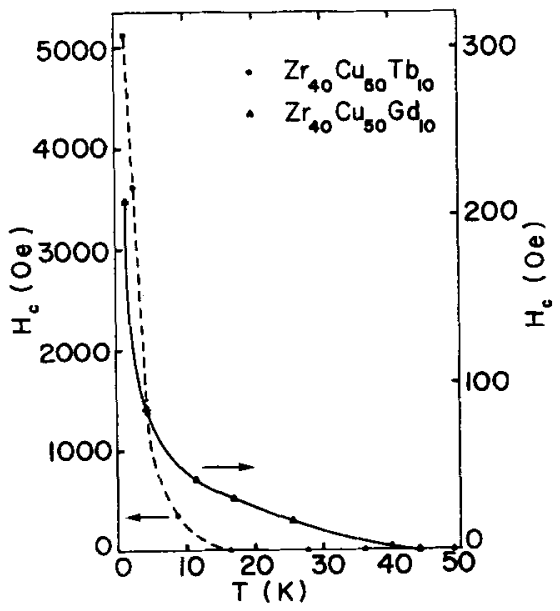

Fig. 3. $\mathrm{H}_{\mathrm{C}}(\mathrm{T})$ for $\mathrm{Zr}_{40} \mathrm{Cu}_{50} \mathrm{Gd}_{10}$ and $\mathrm{Zr}_{40} \mathrm{Cu}_{50} \mathrm{~Tb}_{10}$.

\section{CONCLUDING REMARKS}

The purpose of this paper has been to briefly describe some of the magnetic properties of a few amorphous metalic ic alloys. The data for all the $\mathrm{Zr}-\mathrm{Cu}(M)$ alloys, except for $M=M n$, are consistent with the idea that at low-temperatures the local moments are frozen in directions with a large degree of randomness, i.e., in a spin-glass-like state. It was found that inclusion of crystal-field effects is necessary for understanding the behavior of the Tb atloys.

In many of the samples, magnetic clustering appears to be in evidence even at room temperature. It is not clear whether the magnetic clusters are intrinsic (due to purely random concentration fluctuations) or extrinsic (due to segregation of the impurity atoms).

From the values of the resistivity $(\rho \simeq 350 \mu \Omega \mathrm{cm})$, one can estimate the electron-mean-free path to be of the order of the interatomic distances. That ferromagnetic interimpurity interactions predominate in the rare earth alloys (if not all the alloys) may be due to such extremely short electron-mean-free paths, which effectively eliminate any long-range oscillatory interaction. Under such circumstances, it is certainly possible that interactions of one sign will predominate.

The study of the Gd and Tb alloys was initially motivated by calculations of Harris and Zobin [2] which suggested that whenever ferromagnetic exchange interactions predominate, the strength of the local anisotropy interactions may be crucial in determining whether such alloys will exhibit spin-glass-like behavior. They constructed a phase diagram which indicated that as the uniaxial anisotropy strength is increased a system is driven from random ferromagnetism towards spin-glass-like behavior. Preliminary estimates of $D / J$ [8] suggest that, if these original results of Harris and Zobin were correct, spin-glass-like behavior was predicted for the Tb alloys. That the Tb alloys exhibit such behavior, however, does not verify this theory. This follows because Harris and Zobin ignored fluctuations in $J$ which are present in these al loys and in themselves lead to spin-glass-like order. It should also be noted that subsequent calculations of Harris and Sung [10] and others [3,9] suggest that these spin-glass-like states are at best metastable. A fuller account of the results described above will be published elsewhere.

\section{REFERENCES}

Work supported by National Science Foundation. Present address: South Dakota School of Mines and Technology, Rapid City, South Dakota 57701.

1. A. I. Gubanov, Fiz. Tverd. Tela 2, $502(1960)$.

2. R. Harris and D. Zobin, J. Phys. F 7, 337 (1977).

3. J. D. Patterson and G. R. Gruzaiski, Bull. Am. Phys. Soc. 22, 266 (1977), and J. D. Patterson, G. R. GruzaTski, and D. J. Sellmyer, to be published.

4. M. Ohring and A. Haldipur, Rev. Sci. Instr. 42 , 530 (1971).

5. T. Mizoguchi and T. Kudo, AIP Conf. Proc. 29, $167(1976)$.

6. See, e.g., R. Orbach, AIP Conf. Proc. 24, 3 (1975) and references therein.

7. G. R. Gruzalski, J. W. Weymouth, D. J. Sellmyer, and B. C. Giessen, in Amorphous Magnetism II, R. A. Levy and R. Hasegawa, ed. (Plenum Press, New York, 1977), p. 235

8. G. R. Gruzalski, D. J. Sellmyer, R. Harris, and M. J. Zuckermann, 1977, to be published.

9. M. C. Chi and R. Alben, J. Appt. Phys. 48, 2987 (1977); and E. Callen, Y. J. Liu, and J.R. Cullen, But1. Am. Phys. Soc. 22, 572 (1977), and Phys. Rev. B (in press).

10. R. Harris and S. Sung, private communication. 